\title{
Ah Bing and "The Moon over A Fountain" under the Background of Humanism
}

\author{
Bing $\mathrm{Hu}$ \\ School of Art and Design \\ Xi'an University of Technology \\ Xi'an, China
}

\begin{abstract}
The Moon over a fountain" is an outstanding representative of Chinese traditional music. The research mostly concentrated in the life of Ah Bing, music ontology, performance method and style, temperament and so on. From the perspective of humanism, this article narrates Ah Bing's social and psychological factors and the aesthetic meaning of "The Moon over a fountain".
\end{abstract}

Keywords-Ah Bing; The Moon over a Fountain; regional sociology; psychology; aesthetics

\section{INTRODUCTION}

"The Moon over a fountain" has become the outstanding representative of traditional Chinese music after more than half a century of trial. Its melody is familiar and enjoys popular support. The study of "The Moon over a fountain" has achieved fruitful results both in depth and breadth. The contents of research mainly focus on the life of the songwriter, such as the life of Ah Bing, the style of music, performance method, the style of music and the temperament of music. However, there is little attention paid to the social and humanistic features of "The Moon over a Fountain". This article will elaborate on this classic work from the perspective of regional sociology, psychology and other humanities.

\section{The Ontology StRUCtURE OF MUSIC}

"The moon over a fountain" is also known as "heart song". And it suggests that the song is in accordance with the heart. This song is created by the accumulation of folk music material. And the music structure is refined. It has smooth melody and deep emotion. On the original source of the melody, it has always been controversial. According to Ah Bing's opinion, the song was originally a Taoist Suona song. However, this song does not exist in the Taoist Suona. According to the study of music historians, there are generally no direct sources of folk narration such as "Intimate Couple", "Spring Drama of Suzhou", "Folk Songs of South Jiangsu", and "Drunken Singers" of Taoist music to prove specific source of "The Moon over a fountain". A researcher once held the melody of "The Moon over a fountain" to the old people in Wuxi. And the old people said that it was Wuxi opera music. In a certain area, when local music has some similar sound cavity, musical form and features, they would be classified as musical genre by folk people. In the early 1930s, some citizens heard that Ah Bing had played this song. And it has been over 20 years until Yang Yinliu recorded it. Therefore, one thing is sure. Ah Bing had drawn the essence of for long term. No matter where the music comes from, the characteristics of folk music is obvious.

On the structure of the song, the author agrees with Chen Yingshi's research. He pointed out that the music could be the introduction. And the end should plus five sections [1]. Later, he had added that the song used spin method of biting fish tail. It has adopted the style of adjusting the tone [2]. "The Moon over a fountain" is a variation of the $G$ tone structure. It started with a brief primer. And the descending scale of the primer is like a sigh. It lamented the helplessness and hardships of life. It showed subsequent variations of the theme. And the theme consisted of three phrases. The melody is beauty. The music is smooth. It seems to tell something. The theme laid the foundation for the music composition and mood of the whole song. Through the development methods of folk music with head-to-tail stacking" and "fish tail-biting", the theme has been progressed step by step. Then, we can feel Ah Bing's misery life. Followed by the theme, it added flowers and reduced the variation of four changes in development. With the continuous advancement of the variation structure, emotions burst out. It shows Ah Bing's complaints about the dark social reality and protest against painful life. In the meantime, he added the unique technique of "vibrating bow" of the erhu to talk more about his strong inner feelings and make the listeners feel empathy. The end of the song is the fifth variation. It appears the old material of the theme music. And the end of the sound falls in the consonant and did not fall on the tone. It resulted in a sense of instability. And it expressed unyielding struggle when facing the fate and social darkness. However, he didn't know how to find the right way. The desperate sad mood also leaves the listener space for thinking. The unfinished end verified Ah Bing's tragic life. The music is endless. And it reflected his anger and indignation. Ah Bing used his music to depict his own tragic life.

"The Moon over a fountain" is also title music, which is an inherent characteristic of Chinese traditional music. The title is derived from the discussion between Ah Bing and musician Yang Yinliu. Most of the titles of traditional 
Chinese music seem to have nothing to do with the music. "To make an image is to express connotation". And it often is used in prophecy and sentinel expression. The words "Erquan", "Moonlight" and "Emotion" make up a complete image. In silent night, along the Erquan, Ah Bing tells the hardships and loneliness life. The spring water blended with the moonlight. With the moonlight and emotion, it shaped the three-dimensional and distinctive image. He Luting once said that "The graceful name of "The Moon over a fountain" actually contradicts his music. The music describes the landscape of Erquan. Also, it profoundly expressed the painful experience of blind Ah Bing. With the landscape of Erquan, we would have empathy. When we think of Ah Bing's misery life, we would be touched by the scene. And then, we may experience life flavor. All scenery is language. And the title of "The Moon over a fountain" would be accurate and beautiful.

The five changes used the same material. However, we could feel different mood. Five sections of the music material appear to be the same. Actually, the changes reflected the emotional alternation. His music is touching. And he had lived in painful and stray life in the old society for a long time. His music described his thoughts and feelings in the long-term vagabondage [3]. The complex emotions of Ah Bing were in the music. And the melancholy reappears as the theme changes. Similar music elements overlap, implying the continuous melancholy. We do not know when the sadness would be over. The music is endless.

\section{III. "COUNTRY" AND "PEOPLE"}

\section{A. "The Country" - The Social and Historical Background of Ah Bing's Life}

The life of Ah Bing (1893-1950) coincided with the period of China's change. And "turmoil" became the theme of this period. From the Sino-Japanese War of 1894-1895 to the founding of New China, the warlords and the Japanese army invaded China. Various forces come into play. It can be described as internal and external problems. Ah Bing lived in Wuxi. Of course, he would be influenced by social history and the environment. Wuxi is located in southern Jiangsu. It has always been called the rich land of fish and rice. Also, it is one of the economically developed areas in old China. It is also one of the earliest southern areas where capitalism sprouted. Due to the unique natural conditions and the developed water and land transportation in Wuxi, Wuxi has enjoyed steady economic development with a predominance of agriculture. It would be possible for prosperous citizen culture. In the late Qing dynasty, the early Republic of China was in a semi-colonial and semi-feudal historical period. And the society basically showed a selfsufficient living condition. The foreign invasion war represented by the Opium War and the peasant war represented by the Taiping Heavenly Kingdom made the economic structure of the feudal society rapidly change. Since the Opium War, Wuxi has been forced to open up. Large numbers of technology, industry and culture brought by the West have invaded and fused with each other. As a result, the national industry came into being and flourished gradually. It formed the embryo of modern cities. During the war, due to flourishing development of the national industry, the war brought untold harm to Wuxi. The war-makers would consider vested interests. And they will not devastate the town of Wuxi. Therefore, before the Anti-Japanese War, Wuxi suffered five wars. After each burning, it can quickly recover the economic order. During the Anti-Japanese War, Wuxi was early in the fall. The industry was almost destroyed by the Japanese army. However, after one or two years, under the strict economic control, there were still small-scale workshops, factory clusters, and commercial abnormalities and prosperity [4]. Owing to the great destructive power of the war, the national industry could not contend with it. Under the background of the perennial war in China at that time, the economy in the region of Wuxi showed a difficult situation. Therefore, before the founding of New China, the national industry and the daily production and livelihood of the people in Wuxi had been hit hard. And the losses were immeasurable. This is the untold successor to Wuxi in the southern city of Jiangnan. It was true portrayal of China. Also, it is the "great power" era of Ah Bing's life.

\section{B. "Unimpressive Figure" - The Life Experience of Ah Bing}

1) Ah Bing's rough life: Bing's father is He Huaqing. And his father is a Taoist in Lei Zundian. And he loved the widow $\mathrm{Wu}$. And then, they had Hua Yanjun. The baby was Ah Bing. When Ah Bing was young, his mother died of gossip. Due to feudal ethics, Ah Bing was sent to the village of Dongting Xiaosi in the countryside of Wuxi for foster care. At the age of eight, he was taken back to Lei Zun Temple to become a small Taoist priest who learned art with his father. When his father died in his early twenties, Ah Bing became a new Taoist priest in Lei Zun Temple. After syphilis caused eye disease, one eye was blind. He was forced to leave the Lei Zun Temple. The 35-year-old blind boy was known as the "blind Ah Bing". And he has become a street artist in Wuxi. He married two women and died in 1950 at the age of 57. And his second wife accompanied his left life. It was Dong Cui. Ah Bing's life track depicts his state of life. In the long life of more than fifty years, we can imagine the hardships of his life. Whether sad childhood life, secular discrimination, or blind physical and mental suffering, it had brought a touch of tragic color to the life of Ah Bing. It is the tragedy of the fate of Ah Bing. And Ah Bing deeply understood human nature and the society. And then, we could appreciated sad and moving "The Moon over a fountain".

2) The course of Ah Bing's mind and its influence on "The Moon over a fountain": The life situation of a person plays an important role in the construction of psychological state. Especially, serious life changes and serious psychological trauma have far-reaching impact on the changes of psychological state. In his life, Ah Bing had three major changes. He lost his mother in his early years. And he was fostered in the country. The father died. Then, he left the Taoist. He was blind. Then, he went to have 
vagrancy. These three changes have a deep impact on the daily life of Ah Bing. There must be corresponding mapping and reflection in the psychological state. Perhaps, we can explore his mind course from the perspective of life circumstances. Also, it provides a new direction for the study of "The Moon over a fountain".

At the age of four, Ah Bing's mother died. Childhood is the time when children are most attached to their mothers. It is an important part of the establishment of psychological security. It is related to adult mental health and cognitive ability of behavior. This is a significant psychological loss of Ah Bing in the early years of life. Without the care of his mother, he could easily become impatient, over-anxious, and insecure. Facts have proved that Ah Bing's temper is not good. In the foster care of relatives, it is also a period of selfidentification for young children. They gradually find the strength of self-development from the traumatic experience of reflection. Self-identification is a process of selfidentification and the construction of meaning. Its purpose is to establish one's own "identity" and find one's own "belonging". And then, it would realize the confirmation of "who I am" [5]. Finding a sense of belonging and selfidentity is not easy for Ah Bing. And he is still a child. In the life, he must depend on others. The wanderings of the heart, the sense of having no place to live, and the sense of having no roots are accompanied by Ah Bing. And it is obvious in the period of vagrancy.

Later, the death of his father made Ah Bing's feelings of loneliness is more serious. When parents die, they are likely to cause emotional problems and self-isolation, guilt, emptiness and loneliness without internalization and external assistance. Therefore, it would ascend to the cognition and consciousness. With strong self-condemnation and impulse, the emergence of action, different levels of self-abuse, it would achieve self-psychological re-balance [6]. In order to find a balanced state of self-psychology, when Ah Bing took over the work of his father, he began to degenerate, to go whoring, and to take opium. Eventually, he died of illness. The behavior of Ah Bing is not only due to the enjoyment of life without worries, but also due to the psychological changes caused by the early events. Ah Bing got embarrassed. He had to leave the Tao. And he was blind. The original comfortable life was gone forever. And now, Ah Bing had to rely on the art to make the living. Ah Bing's heart will inevitably have a gap. This kind of psychological state of trauma was directly affected by the external environment. It would produce a series of changes in character, mood, body, and so on. Different people have different reactions to psychological trauma. Due to the limitations of personal ideology, Ah Bing continued to degenerate. In the end, he became blind.

After being blinded, Ah Bing cut off almost all sources of living. He sold the arts to maintain the basic life. The blind have a lot of inconvenience in life. They are more delicate and sensitive than the healthy people. And the self-esteem is stronger. They will try to cover up their own defects. With dark glasses, Ah Bing wants to cover up the inferiority of the heart. Due to the limitation of vision, the movement would be difficulty. The long-term eye disease torment is more likely to form the desolate grumpy disposition. The life of vagrancy and poverty is even worse. Such a state of life and continuing psychological trauma accompanied Ah Bing in the second half of his life. People's character is multistructured. What is worth to say, Ah Bing will show that he is upright. And he wouldn't flatter the power of the influential officials. Whenever he heard about the bad news and bullying, he would sang the news ironically. It is similar to rap. In a lonely environment, Ah Bing can give everyone a positive force. For Ah Bing, such shining points are particularly precious.

We can't know where this piece of music came from. As Ah Bing said, this piece of music is called "song from the heart". And everyone also calls it "song from the heart". Its creation has a direct relationship with Ah Bing's life circumstances. After selling art for a day, Ah Bing played the song with $\mathrm{Hu}$ Qin in the alley at night. It is sad. It seems to tell their own wanderings of the heart and life. The painful life of Ah Bing and the life at the bottom of the society are the creative motive of "The Moon over a fountain". Ah Bing's mental journey and rough life are the source of "The Moon over a fountain". It becomes a classic work. In the life of grass-roots vagrancy, Ah Bing used Hu Qin to pull out the sad song of his heart. It told the sincere feeling. The sorrowful sound of "The Moon over a fountain" would be in every corner of Wuxi city.

\section{INTERACTION BETWEEN SOCIETY AND INDIVIDUAL}

With the changing social environment, it not only brought Ah Bing light, but also brought suffering.

\section{A. The Nourishment of Folk Music}

From an early age, folk music put a deep brand on Ah Bing. There is a strong atmosphere of folk music in Dong Ting Xiao Si which fostered Ah Bing. Ah Bing absorbed the nutrition of blowing in Southern Jiangsu, traditional stringed and woodwind instruments in Jiangnan, Kunqu opera, music in Guangdong, local opera and folk minor. This folk music deeply rooted in Ah Bing's heart, flowing in his blood. When Ah Bing returned to Taoism, in addition to his father teaching Erhu and pipa, such Taoist music as Brahma, rap, and beach spring also nourished Ah Bing. Folk music and religious music accompanied him throughout his life. When he spoke of the origin of "The Moon over a fountain", he said, "Maybe it was learned from Taoism," and "Maybe it was heard from the street". Folk music imperceptibly influenced Ah Bing. Also, it gave birth to "The Moon over a fountain".

\section{B. The Pain from the Lower Class}

Whether it is in Taoism or wandering, the identity of Ah Bing has not changed much. The Taoist priest's status is slightly higher than the roaming artists. Basically, they all belong to the lower class of society. Ah Bing suffered from the supercilious look. He tasted the cold and warm of the world. Originally, he became a Taoist priest. The incense money could afford his food and clothing. And he chose to play the life. In the process of contacting with society, it had 
the three religions and the nine schools of thought. And it is decided by the bottom of the social environment. Birds of a feather flock together. People of similar ideologies infected Ah Bing with bad social habits such as seeking carnal pleasure, and visiting private tobacco. Later, incense money was used up. Also, it caused venereal disease. He was blind on the street. Ah Bing's social status plummeted from being a Taoist priest into a wandering entertainer. From being selfsufficient into a poor man, this result is partly due to Ah Bing's indulgence on his own, his misfortune in life and his psychological changes. On the other hand, the underlying social pleasure mentality affected Ah Bing. The bad atmosphere of the lower class society shook the innermost feelings of Ah Bing's insistence. It not only made Ah Bing have no food and clothing, but also destroyed an excellent folk musician.

\section{Ah Bing's Feelings for Family and Country}

As a small person, Ah Bing shows his love for his hometown and country with his own little strength. During the Anti-Japanese War, when the foreign powers invaded, the nation was beaten black and blue. The people were injured, and the motherland was in emergency. Ah Bing should be proud of himself and defended the interests of the "big countries" with practical actions. Not only did he sing the news into rhyming words, propagate anti-Japanese ideas in the style of "talking about the news", he also used musical instruments to play patriotic songs and conveyed his enthusiasm for fighting against foreign aggression and protecting the country. "The Nineteenth Route Army bravely fought the enemy in Shanghai," "The March of the Volunteer Army" and "the Songhua River" is his masterpieces. Some people advised him to go to the dance hall in Shanghai to play the piano and trade his dignity for more money. Ah Bing refused and insisted on staying in his hometown to play for the people in his hometown. Even though he was slapped, he did not want to play for the Japanese and puppet army officers. And Ah Bing showed his national integrity. During the Civil War, Ah Bing exposed the reactionary plot and darkness. He was wounded and ruined his musical instrument. And he was not afraid. The backbone of Ah Bing shows that ordinary people love their homeland and their country. Although he is a low-class artist, this does not prevent Ah Bing from playing his patriotic emotion. The Patriotic emotion has no class. Even though he has bad habits, Ah Bing's heart shows his uppercase feelings.

Ah Bing, who lives in Wuxi, is inseparable from his hometown. And his hometown also gave Ah Bing life "gift". Whether good or bad, Ah Bing must accept it. One side of soil and water support one side of the people. "Big country" and "small people" depend on each other. They can't be separated.

\section{CONCLUSION}

"The Moon over a fountain" absorbs the essence of folk music. From the beginning to end, it tells the story of the emotional and life of Ah Bing in the bottom of the society. It used the moonlight, spring and roaming artists to construct the image of the infinite artistic conception. Its lyrical language expresses the beauty of Chinese traditional music. It has profound ideological content and great artistic appeal.

The strong and powerful voice in "The Moon over a fountain" is the embodiment of Ah Bing's unyielding fate and constant struggle. However, this kind of struggle can't change the life of Ah Bing, nor can the spirit of Ah Bing find a bright exit. What makes Ah Bing feel disappointed is the huge contradiction between the reality of poor life and the spirit of non-yielding. He wanted to fight and break away from the prison of suffering. However, he was unable to find the end of darkness and spiritual comfort. The sociological and psychological analysis of "The Moon over a fountain" presents a new perspective for us to understand Ah Bing and his works. Whether personal fate or the fate of the country, it showed a profound tragic era.

\section{REFERENCES}

[1] Chen Yingshi. On the music structure of Chinese folk songs [J]. People's Music. 1963 (2)

[2] Chen Yingshi. The music structure of "The Moon over a fountain" and others [J]. Music Art. 1994 (1)

[3] Zhang Jingbo. The creative source and artistic achievement of "The Moon over a fountain" [J]. Journal of Nantong Teachers College (Philosophy and Social Science Issue) 2003 (3)

[4] Li Honggang. On the modernization of Wuxi economy [J]. Jiangsu Newsfeed. 1988 (Z2)

[5] Wu Yujun, Li Xiaodong. The lack of sense of belonging: the predicament of identity under the context of modernity [J]. 2005(5)

[6] Peng Rongbang. Distressed: miss the world's placement and comfort [D]. Hualian: Institute of Ethnic Relations and Culture of Donghua University. 2000 